\title{
Determinants of Care Costs of Patients With Dementia or Cognitive Impairment
}

Citation for published version (APA):

Handels, R. L. H., Wolfs, C. A. G., Aalten, P., Verhey, F. R. J., \& Severens, J. L. (2013). Determinants of Care Costs of Patients With Dementia or Cognitive Impairment. Alzheimer Disease \& Associated Disorders, 27(1), 30-36. https://doi.org/10.1097/WAD.0b013e318242da1d

Document status and date:

Published: 01/01/2013

DOI:

10.1097/WAD.0b013e318242da1d

Document Version:

Publisher's PDF, also known as Version of record

Document license:

Taverne

Please check the document version of this publication:

- A submitted manuscript is the version of the article upon submission and before peer-review. There can be important differences between the submitted version and the official published version of record.

People interested in the research are advised to contact the author for the final version of the publication, or visit the DOI to the publisher's website.

- The final author version and the galley proof are versions of the publication after peer review.

- The final published version features the final layout of the paper including the volume, issue and page numbers.

Link to publication

\footnotetext{
General rights rights.

- You may freely distribute the URL identifying the publication in the public portal. please follow below link for the End User Agreement:

www.umlib.nl/taverne-license

Take down policy

If you believe that this document breaches copyright please contact us at:

repository@maastrichtuniversity.nl

providing details and we will investigate your claim.
}

Copyright and moral rights for the publications made accessible in the public portal are retained by the authors and/or other copyright owners and it is a condition of accessing publications that users recognise and abide by the legal requirements associated with these

- Users may download and print one copy of any publication from the public portal for the purpose of private study or research.

- You may not further distribute the material or use it for any profit-making activity or commercial gain

If the publication is distributed under the terms of Article $25 \mathrm{fa}$ of the Dutch Copyright Act, indicated by the "Taverne" license above, 


\title{
Determinants of Care Costs of Patients With Dementia or Cognitive Impairment
}

\author{
Ron L. H. Handels, MSc, ${ }^{*}$ Claire A. G. Wolfs, PhD, ${ }^{*}$ Pauline Aalten, PhD, ${ }^{*}$ \\ Frans R. J. Verhey, PhD, MD,* and Johan L. Severens, PhD †
}

\begin{abstract}
Introduction: Dementia causes a high burden on patients, caregivers, and societies. Decision analytic models to support allocation of resources are often developed making use of cost-of-illness (COI) studies. However, current COI study estimates are highly variable due to care setting and methodological issues. We aim to explore variables explaining the variation of (formal and informal) health care costs of cognitive disorders, using a broad spectrum of variables, including patient, caregiver, and social context variables.
\end{abstract}

Methods: A bottom-up COI study design was used in which a societal viewpoint and a validated method to measure and value informal care was applied. Data were analyzed using univariate, multivariate, and forward regression analyses.

Results: The average 1-year health care sector costs were $€ 26,140$ $(\$ 34,505$ or $£ 17,775)$ and $€ 11,931$ ( $\$ 15,749$ or $£ 8113)$ for patient and family. The analyses indicated that cognitive functioning, caregiver burden, patient sex, and instrumental activities of daily living were significantly associated with care costs independently.

Conclusions: Cognitive functioning and instrumental activities of daily living are important variables to include in health care decision models. We recommend also including caregiver burden and patient sex in decision models for health policy decision makers to fully reflect the heterogeneity of the disease progression of cognitive disorders.

Key Words: dementia, Alzheimer disease, caregiver burden, decision analytic modeling, economics, cost-of-illness study

(Alzheimer Dis Assoc Disord 2013;27:30-36)

A lzheimer disease (AD) and related dementias affect cognitive function, functional ability, and behavior and could result in a major impact on the quality of a patient's life. Worldwide, 35.6 million persons were estimated to suffer from AD and other dementias in 2010, and this number is predicted to double within the next 20 years. The costs of dementia are estimated at US\$604 billion. ${ }^{1}$ Because health care resources are scarce, informed decision making on health care management and efficiently allocating resources are important to minimize loss of opportunities. To

Received for publication May 18, 2011; accepted November 15, 2011. From the *Alzheimer Centre Limburg, School for Mental Health and Neuroscience (MHeNS), University Medical Centre, AZ Maastricht; †Department of Health Organization, Policy and Economics, Faculty of Health Medicine and Life Sciences, CAPHRI School for Public Health and Primary Care, Maastricht University, MD Maastricht; and \$Institute of Health Policy and Management, Erasmus University Rotterdam, DR Rotterdam, The Netherlands. The authors declare no conflicts of interest.

Reprints: Ron Leonardus Hubertus Handels, Department of Psychiatry and Neuropsychology, University Hospital of Maastricht/ Alzheimer Centre Limburg, P.O. Box 5800, 6202 AZ Maastricht, The Netherlands (e-mail: ron.handels@maastrichtuniversity.nl). Copyright (C) 2013 by Lippincott Williams \& Wilkins inform decision makers, several methods to evaluate care interventions are available, among which are trial-based economic evaluations and decision analytic modeling. The first method measures the costs and health care outcomes alongside a clinical trial; the latter provides a framework combining available evidence from different resources. A decision analytic model can be defined as a set of mathematical relationships to form a structure that reflects the natural history of a disease with which the effects of an intervention can be estimated. It enables the calculation of the likelihood of each consequence and its corresponding costs and effects by simulating patients or fractions of a population. $^{2}$ In order to build a decision model, information is needed on the relative effect of disease determinants on care costs. Such information can be found in cost-of-illness (COI) studies. ${ }^{3}$ This implies that the external validity or the generalizability of decision analytic models, and with that the health care decisions made by policy makers, depends on the quality of COI studies used for decision models.

Several reviews on COI studies have been performed in the field of dementia ${ }^{4-6}$ on the basis of 39 COI studies. The total annual costs of care per person suffering from AD and other dementias show a considerable amount of variation, ${ }^{5}$ ranging from $€ 6614$ to $€ 64,426$ in northern and western European countries. ${ }^{4}$ To improve COI studies for decision making, it was recommended to use a validated method for the assessment of informal care and to provide an adequate patient sample within each country and care setting. ${ }^{4,6}$ We retrieved 1 additional study ${ }^{7}$ to the reviews and found that none of the studies identified the independent effect of a broad spectrum of patient disease characteristics and both patient and caregiver social context characteristics, and thus it does insufficient justice to the complexity of the disease to use the results for disease modeling. To reflect a coherent theory of the complex concept of dementia and its treatment, a model used for decision making should include the effects on cognitive function, functional ability, and behavioral problems. This is important in building decision models for care management, as was indicated by 2 recent reviews in the field of decision analytic modeling of AD. ${ }^{8,9}$

Therefore, we aim to explore variables for explaining the variation of health care costs in dementia and cognitively impaired patients, using a broad spectrum of variables, including patient disease and patient and caregiver social context variables. This will provide the relative value of the determinants of care costs for cognitive disorders.

\section{METHODS}

Dutch patient-level care cost data were used, from a societal viewpoint (including direct and indirect health care 
costs and costs made on other sectors), and validated methods were used to evaluate informal care. We analyzed the data of 219 patients and their informal caregivers who participated in the Maastricht Evaluation of a Diagnostic Intervention for Cognitively Impaired Elderly (MEDICIE) study. General practitioners from 70 practices in the southern part of The Netherlands were asked to refer all 55 years or older patients, suspected of having dementia or a cognitive disorder, not living in a nursing home, and not suffering from an acute disorder from July 2002 to August 2004. The MEDICIE study was published previously. ${ }^{10,11}$ In short, the clinical effects and cost effectiveness of an integrated multidisciplinary diagnostic facility for patients with cognitive disorders were examined in a randomizedcontrolled trial in which the control group received monodisciplinary usual care. All outcome measures, except for the mini-mental state examination (MMSE) ${ }^{12}$ and activities of daily living, were collected through interviews with the patient's proxy, who was also the informal caregiver (ie, proxy's perception of the patient's health was measured). The current study used data of both the intervention and the control group from a 1-year follow-up period. A bottom-up COI design was applied. In such a design, care resource consumption or care costs are measured from a sample of patients and generalized to the total population of the disease under evaluation.

\section{Data Collection}

Several baseline outcome measures of the MEDICIE study were used. The MMSE was used to reflect the severity of cognitive function, the Neuropsychiatric Inventory $(\mathrm{NPI})^{13}$ to reflect neuropsychiatric symptoms, and the Instrumental Activities of Daily Living scale (IADL) ${ }^{14}$ to reflect daily life. Health-related quality of life was measured by the EQ-5D, ${ }^{15}$ a validated instrument providing a simple descriptive profile and a single index value for health status. It also includes a visual analogue scale, ranging from 0 (worst imaginable health state) to 100 (best imaginable health state). The experienced caregiver burden was measured by the Self-Perceived Pressure from Informal Care questionnaire (SPPIC), ${ }^{16}$ a 9 -item scale that measures perceived stress caused by informal caregiving to the demands of the caregiving situation.

Patient characteristics included sex, age, living situation (living together with informal caregiver), diagnosis, and number of comorbidities. The diagnosis was classified as dementia or not. A diagnosis of dementia was specified as $\mathrm{AD}$, vascular dementia, mixed $\mathrm{AD}$ and vascular dementia, other dementia, or other cognitive impairment according to regular guidelines. The number of comorbidities of the patient was measured in 2 different ways. First, the number of diseases on the third axis of the Diagnostic and Statistical Manual of Mental Disorders IV ${ }^{17}$ diagnosis, as determined by the clinician, was counted and used as an objective measurement of the patient's comorbidities. Second, the informal caregiver was asked to score the presence of several diseases during the interview to obtain a subjective measure of comorbidities. Informal caregiver characteristics included sex, age, experienced burden, number of comorbidities (obtained from caregiver interviews), relation with patient, marital status, education, and net family income.

Because of high correlations and to enhance comparability with other studies, the diagnosis of dementia (yes/no) instead of the differential diagnosis was used for
TABLE 1. Sample Characteristics at Baseline of 219 Patients and Informal Caregivers

\begin{tabular}{|c|c|c|}
\hline Characteristics & $\begin{array}{l}\text { Frequency and } \\
\text { Percentage }\end{array}$ & $\begin{array}{l}\text { Average } \\
\text { and SD }\end{array}$ \\
\hline Female & $43(65 \%)$ & - \\
\hline & & $78(6.7)$ \\
\hline osis of dementia & $158(72 \%)$ & - \\
\hline VAS score $(0-10)^{*}$ & - & $5.8(1.9)$ \\
\hline & - & $5.2(3.2)$ \\
\hline & - & $20.0(5.8)$ \\
\hline 4) & - & 23.9 (16.6) \\
\hline 4) & - & 2.1) \\
\hline $\begin{array}{l}\text { No. comorbidities of the patient, } \\
\text { objectively measured }\end{array}$ & - & $3.1(1.9)$ \\
\hline $\begin{array}{l}\text { No. comorbidities of the patient, } \\
\text { subjectively measured }\end{array}$ & - & $3.6(2.4)$ \\
\hline $\begin{array}{l}\text { Patient and informal caregiver live } \\
\text { together }\end{array}$ & $88(40 \%)$ & - \\
\hline formal caregiver & $145(66 \%)$ & - \\
\hline & - & $59.5(14.1)$ \\
\hline ) & $117(53 \%)$ & \\
\hline & - & $4.6(2.8)$ \\
\hline $\begin{array}{l}\text { No. comorbidities of informal } \\
\text { caregiver, subjectively measured }\end{array}$ & - & $2.0(2.2)$ \\
\hline Informal caregiver has spouse & $170\left(77^{\circ}\right.$ & - \\
\hline 1 caregiver: & $115(53 \%)$ & - \\
\hline High net family income§ & $97(57 \%)$ & - \\
\hline \multicolumn{3}{|c|}{ 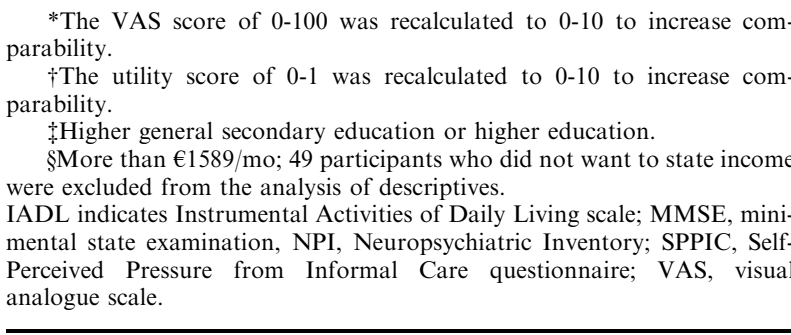 } \\
\hline
\end{tabular}

analysis. Likewise, living situation instead of relation between informal caregiver and patient was used. For the same reasons, Global Deterioration Scale scores, Cornell Scale for Depression in Dementia scores, and scores of the 4 items of the 36-item Short Form Health Survey, which were measured in the MEDICIE study, were excluded for this analysis.

\section{Cost Estimates}

The costs in the MEDICIE study were determined according to Dutch guidelines ${ }^{18}$ from a societal perspective in which all health care costs and health-related patient and family costs were included, regardless of their source of payment. Costs were expressed in euros at 2005 values (at that time, $€ 1.00$ was equivalent to US\$1.32 and British $£ 0.68)$.

Volumes of resource use during the 1-year follow-up period after the diagnosis were measured and multiplied by the costs per resource unit. The volumes of resource use were determined by the hospital information system, the electronic patient files of the local community mental health team, the registries of local pharmacies, an informal care survey, and cost diaries.

Informal care activities were assessed using a survey that had been developed for the measurement of informal care $^{19,20}$ and valued according to the proxy good method. The average time spent on 16 different informal care tasks 


\begin{tabular}{|c|c|c|c|c|}
\hline Cost Item* & No. $(\%)$ of Patients $\dagger$ & Mean Visits & Mean Costs $\S$ & Credibility Interval $\|$ \\
\hline \multicolumn{5}{|l|}{ Health care sector costs } \\
\hline Hospital (A) & $166(76)$ & NA & $€ 2875$ & $2654-3114$ \\
\hline CMHT (B) & $148(68)$ & 8.4 & $€ 1073$ & $1014-1135$ \\
\hline Medication $(\mathrm{C}, \mathrm{E})$ & $215(98)$ & NA & $€ 1505$ & 1444-1566 \\
\hline \multicolumn{5}{|l|}{ Admission (D) } \\
\hline Nursing home & $33(15)$ & 28.8 & $€ 6143$ & $5469-6885$ \\
\hline Elderly home & $34(16)$ & 38.9 & $€ 3475$ & 3056-3859 \\
\hline \multicolumn{5}{|l|}{ Home care (D) } \\
\hline Domestic help & $122(56)$ & 91.1 & $€ 2038$ & 1924-2151 \\
\hline Nursing & $112(51)$ & 98.9 & $€ 4154$ & $3790-4547$ \\
\hline \multicolumn{5}{|l|}{ Day care (D) } \\
\hline In nursing home & $34(16)$ & 11.6 & $€ 1442$ & $1268-1633$ \\
\hline In elderly home & $64(29)$ & 28.2 & $€ 1448$ & $1322-1598$ \\
\hline In community center & $10(5)$ & 3.8 & $€ 11$ & $9-14$ \\
\hline GP $(E)$ & $195(89)$ & 23.9 & $€ 512$ & $488-533$ \\
\hline Other professionals (E) & $150(68)$ & 52.4 & $€ 1462$ & $1392-1530$ \\
\hline \multicolumn{5}{|l|}{ Patient and family costs } \\
\hline Informal care (D) & $219(100)$ & 839.7 & $€ 6620$ & $6151-7015$ \\
\hline Housekeeper (D) & $149(68)$ & 87.3 & $€ 657$ & $622-691$ \\
\hline Durable goods (E) & $100(46)$ & NA & $€ 486$ & $454-518$ \\
\hline Consumable goods (E) & $151(69)$ & NA & $€ 160$ & $154-168$ \\
\hline Out-of-pocket patient (E) & $155(71)$ & NA & $€ 1099$ & $1057-1142$ \\
\hline Out-of-pocket caregiver (D) & $196(89)$ & NA & $€ 2262$ & $2201-2325$ \\
\hline \multicolumn{5}{|l|}{ Traveling costs } \\
\hline To GP and other professionals & NA & NA & $€ 36$ & $34-37$ \\
\hline To hospital (A) & NA & NA & $€ 10$ & $9-10$ \\
\hline To day care (D) & NA & NA & $€ 592$ & $551-635$ \\
\hline Parking costs (A) & NA & NA & $€ 10$ & $9-11$ \\
\hline \multicolumn{5}{|l|}{ Summed costs } \\
\hline \multirow[t]{3}{*}{ Mean total health care sector costs } & - & - & $€ 26,140$ & $25,510-26,796$ \\
\hline & - & - & $\$ 34,505$ & $33,673-35,371$ \\
\hline & - & - & $£ 17,775$ & $17,347-18,221$ \\
\hline \multirow[t]{3}{*}{ Mean total patient and family costs } & - & - & $€ 11,931$ & $11,571-12,368$ \\
\hline & - & - & $\$ 15,749$ & $15,274-16,326$ \\
\hline & - & - & $£ 8113$ & 7868-8410 \\
\hline \multirow[t]{3}{*}{ Mean total societal care costs } & - & - & $€ 38,071$ & $36,893-39,435$ \\
\hline & - & - & $\$ 50,254$ & $48,699-52,054$ \\
\hline & - & - & $£ 25,888$ & $25,087-26,816$ \\
\hline
\end{tabular}

*Source of volume information is given in parentheses: A, hospital information system; B, electronic patient file, CMHT; C, registries of local pharmacies; D, informal care questionnaire; and E, cost diaries. See the "Methods" section for more information.

$\dagger$ Number of patients and the percentage of the total group that made use of the specific item.

\$Mean visits per patient.

$\S$ Mean costs per patient, $€$.

$\| 2.5$ th and 97.5 th percentile credibility interval of 1000 bootstrap replications.

CMHT indicates community mental health team; GP, general practitioner; NA, not applicable.

was assessed at baseline and at the 6- and the 12-month follow-up and multiplied by the hourly wage rate of a housekeeper $(€ 8.54)$ or a nurse $(€ 32.67)^{18}$ depending on the nature of the activity.

None of the patients had a paid job, and therefore, work loss in all patients was 0 . Work loss of the informal caregiver is included as the time spent caring reimbursed at the wage rate of a professional caregiver.

Annual cost estimates were corrected for intervention costs by subtracting these from the total costs for each patient in the intervention group. Costs are often highly skewed to the right ${ }^{21}$ because high care consumption is often concentrated to a small part of the cohort. Therefore, bootstrap credibility intervals were calculated on the basis of 1000 replications; the 2.5 and 97.5 percentiles are presented. More information on the cost analysis can be found elsewhere. ${ }^{10}$

\section{Analyses}

To solve the problem of missing data, 10 data sets were created using multiple imputation according to the linear and logistic regression algorithm of SPSS version 17.0. For all analyses, a $P$-value $<0.05$ was considered statistically significant unless stated otherwise.

The total costs were skewed to the right (skewness = 0.96 and the Shapiro-Wilk test was significant in all imputation sets). A log transformation did not resolve the skewed data. After computing the square root of the costs, skewness $(=0.19)$ was not significant in 9 and the ShapiroWilk test in 7 imputation sets. Regression coefficients were back transformed to estimate the effect on actual costs. These estimates apply when the average cost of a variable increases 1 unit of change. Generalization to other situations should be carried out with caution. It is beyond the scope of this analysis to determine the actual value of 
determinants of care costs. Visual assessment of Q-Q plots and histograms indicated an improvement toward normally distributed data.

Descriptive statistics were applied to all variables. Three different regression models were built using baseline characteristics to determine 1-year follow-up total societal care costs. First, all variables were individually tested using univariate regression analyses and only those variables with a $P$-value $<0.10$ were included in a multiple regression model (model 1). Second, a forward regression method (model 2) was performed on each data set using the same significant variables as those selected for the multivariate regression analysis. A variable that proved significant in at least 5 of 10 data sets was considered a priori a relevant cost predictor. Third, because a stepwise method is solely based on statistics, ${ }^{22}$ only variables that were considered to be theoretically relevant for economic decision modeling were included for a multivariate regression analysis (model 3). As described in the introduction, these measures are cognitive function (MMSE), functional ability (IADL), and behavioral problems (NPI). Further, caregiver burden (SPPIC) has been indicated to increase caregiving time and informal care costs ${ }^{23,24}$ and was therefore included in this model to assess the effect on total care costs. Expert opinion of coauthors confirmed the face validity of these variables.

\section{RESULTS}

\section{Descriptives}

Data were missing on the variables spouse of informal caregiver $(11 \%)$, education of the informal caregiver $(11 \%)$, patient's objective comorbidities $(5 \%)$, and patient's and caregiver's subjective comorbidities (both 12\%). Patients with incomplete data did not differ significantly from patients with complete data.

Table 1 presents the sample characteristics at baseline. The average patient age was 78 years, ranging from 55 to 94 years, and the mean MMSE score was 20.0 $(\mathrm{SD}=5.8)$. Most patients suffered from dementia $(72 \%)$. The informal caregiver was mainly the son or the daughter $(53 \%)$ and spent on average $8.5 \mathrm{~h} / \mathrm{wk}$ providing care to the patient.

Table 2 provides a detailed cost overview on the basis of the data of the MEDICIE study. ${ }^{11}$ The 1-year sample average health care and health-related patient family costs were $€ 38,071$ (or $\$ 50,254$ or $£ 25,888$ ) (95\% bootstrap credibility interval $=€ 36,893-€ 39,435)$. The major cost components were admission to a nursing home ( $€ 6143$ or $\$ 8109$ or $£ 4177)$ and informal care $(€ 6620$ or $\$ 8738$ or $£ 4502$ ), contributing toward $34 \%$ of the total costs. The interval reflects the 2.5 th and 97.5 th percentile confidence intervals.

\section{Regression Analyses}

In both the first and the third regression analysis, multi collinearity was evaluated and was not present. Visual assessment of standardized residual plots and normal probability plots did not imply a violation of the assumption of homoskedasticity or the assumption of normally distributed residuals.

The results of the individual univariate regression analyses are shown in Table 3. This table presents the pooled results of the 10 data sets. A positive direction of the $\beta$-value indicates an increase in cost. The variables age and the objective number of comorbidities of the patient and
TABLE 3. Pooled Results of the Individual Univariate Regression of 1-year Square Root Total Care Costs

\begin{tabular}{lrc}
\hline Variable & Beta & $\boldsymbol{P}$ \\
\hline Female $(1=$ yes, $0=$ no) & 26.13 & 0.01 \\
Age $(y)$ & 1.31 & 0.06 \\
Diagnosis $(1=$ dementia, $0=$ no dementia) & 30.22 & 0.00 \\
EQ-5D VAS score $(0-10)^{*}$ & -9.95 & 0.00 \\
EQ-5D utility score $(0-10) \dagger$ & -8.08 & 0.00 \\
MMSE score $(0-30)$ & -3.79 & 0.00 \\
NPI score $(0-144)$ & 1.51 & 0.00 \\
IADL score $(0-14)$ & -11.23 & 0.00 \\
No. comorbidities of the patient, objectively & 2.80 & 0.29 \\
$\quad$ measured & 4.34 & 0.04 \\
No. comorbidities of the patient, subjectively & & \\
$\quad$ measured & -24.12 & 0.02 \\
Patient and informal caregiver live together & & \\
$\quad(1=$ yes, $0=$ no) & 10.33 & 0.30 \\
Female informal caregiver $(1=$ yes, $0=$ no) & -0.12 & 0.73 \\
Age informal caregiver $(y)$ & 9.76 & 0.00 \\
SPPIC score $(0-9)$ & 2.49 & 0.29 \\
No. comorbidities of informal caregiver, & & \\
$\quad$ subjectively measured & -10.27 & 0.43 \\
Informal caregiver has spouse $(1=$ yes, & & \\
$\quad 0=$ no) & 9.24 & 0.33 \\
High education informal caregiver $\ddagger(1=$ yes, & & \\
$\quad 0=$ no) & 7.03 & 0.62 \\
High net family income $(1=$ yes, $0=$ no) &
\end{tabular}

*The VAS score of 0-100 was recalculated to 0-10 to increase comparability.

$\dagger$ The utility score of $0-1$ was recalculated to $0-10$ to increase comparability.

\$Higher general secondary education or higher education.

\$More than $€ 1589 / \mathrm{mo}$.

IADL indicates Instrumental Activities of Daily Living scale; MMSE, minimental state examination, NPI, Neuropsychiatric Inventory; SPPIC, SelfPerceived Pressure from Informal Care questionnaire; VAS, visual analogue scale.

age, subjective number of comorbidities, spouse, education, and net family income of the informal caregiver were not significant $(P>0.10)$ and were therefore excluded from further analyses.

The results of the multivariate regression (model 1) on the basis of the significance of individual univariate regression analyses are presented in Table 4. Patient sex, cognition (MMSE), functioning (IADL), and SPPIC determined the total care costs. Again, a positive direction of the $\beta$ indicates an increase in cost. This model explained $34 \%$ of the variation in the total costs $\left(\mathrm{R}^{2}=0.34\right)$.

The results of the forward regression (model 2) are shown in the last column of Table 4 . For each variable, it is shown in how many of the 10 data sets this variable is significant in the forward regression analyses (eg, MMSE is significant in 9 of 10 forward analyses). Sex of the patient, the EQ-5D utility score, MMSE, IADL, living situation, and SPPIC significantly contributed toward the square root total care costs of patients in at least 5 imputation sets and were therefore considered to be relevant cost predictors.

The multivariate regression (model 3) is presented in Table 5. All variables except IADL significantly predicted costs. This model explained $28 \%$ of the variation in square root total care costs $\left(\mathrm{R}^{2}=0.28\right)$.

The overall results of all 3 analyses indicated that MMSE and SPPIC were significant predictors of the 1-year square root total care costs. Patient sex and IADL were 
TABLE 4. Pooled Results of the Multivariate Regression Model and Forward Regression Results of 10 Imputation Sets of 1-year Square Root Total Care Costs

\begin{tabular}{|c|c|c|c|c|c|}
\hline \multirow[b]{2}{*}{ Variables } & \multicolumn{4}{|c|}{ Multivariate Regression } & \multirow[b]{2}{*}{$\begin{array}{c}\text { Forward } \\
\text { Regression } \dagger\end{array}$} \\
\hline & Beta & $\boldsymbol{P}$ & $\begin{array}{c}\text { Back- } \\
\text { transformed } \beta^{*}\end{array}$ & $\begin{array}{c}\text { Confidence Interval } \\
\text { Back-transformed } \boldsymbol{\beta}^{*}\end{array}$ & \\
\hline Female $(1=$ yes, $0=$ no $)$ & 25.9 & 0.02 & 10,120 & 1936 to 18,304 & 7 \\
\hline Age & -0.2 & 0.73 & -82 & -533 to 369 & 0 \\
\hline Diagnosis $(1=$ dementia, $0=$ no dementia $)$ & -5.0 & 0.64 & -1816 & -8619 to 4988 & 0 \\
\hline EQ-5D VAS score $(0-100)$ & 0.2 & 0.55 & 60 & -134 to 254 & 0 \\
\hline EQ-5D utility score $(0-1)$ & -21.5 & 0.24 & -7396 & $-19,072$ to 4279 & 7 \\
\hline MMSE score $(0-30)$ & -1.9 & 0.03 & -701 & -1276 to -126 & 9 \\
\hline NPI score $(0-144)$ & 0.5 & 0.12 & 173 & -34 to 380 & 4 \\
\hline IADL score $(0-14)$ & -6.7 & 0.01 & -2396 & -4170 to -621 & 7 \\
\hline $\begin{array}{l}\text { No. comorbidities of the patient, subjectively } \\
\text { measured }\end{array}$ & 0.6 & 0.76 & 233 & -1061 to 1527 & 0 \\
\hline $\begin{array}{l}\text { Patient and informal caregiver live together } \\
\qquad(1=\text { yes, } 0=\text { no })\end{array}$ & -13.7 & 0.16 & -4811 & $-11,015$ to 1393 & 6 \\
\hline SPPIC score $(0-9)$ & 6.3 & 0.00 & 2357 & 1146 to 3568 & 10 \\
\hline Constant & 215.1 & 0.00 & - & - & - \\
\hline
\end{tabular}

*Back-transformed costs were estimated by calculating the effect on costs if the average variable value increased by 1 using the following equations for back transformation; equation 1 for the cost estimate, equation 2 for the variance to calculate the confidence interval.

$\dagger$ Number of models in which variable is significant.

$$
\begin{gathered}
E=\left(\sum_{i}\left(C+\beta_{\mathrm{t}} x_{\mathrm{t}}+\beta_{i} x_{i}\right)\right)^{2}-\left(\sum_{i}\left(C+\beta_{\mathrm{t}} x_{(\mathrm{t}+1)}+\beta_{i} x_{i}\right)\right)^{2} \\
\operatorname{var}_{E}=4(C+\beta)^{2} \operatorname{var}_{\beta}+4 \beta^{2} \operatorname{var}_{C}+4 \beta(C+\beta) \operatorname{cov}(C, \beta)
\end{gathered}
$$

$E$, cost estimate of back-transformed beta; $C$, constant; $\beta_{\mathrm{t}}$, beta of the variable to back transform; $\beta_{i}$, beta of variable $i$ in the regression formula; $x_{\mathrm{t}}$, average value of the variable to back transform; $x_{(\mathrm{t}+1)}$, average value of the variable to back transform increased with $1 ; x_{i}$, average values of variable $i$; var ${ }_{E}$, variance of a back-transformed estimate; $\operatorname{var}_{C}$, variance of the constant; $\operatorname{var}_{\beta}$, variance of the beta; $\operatorname{cov}(C, \beta)$, covariance between constant and beta.

To properly calculate the estimated total costs for a certain set of values for the covariates, a smearing factor must be applied. ${ }^{25}$ However, in case of square root transformations, this smearing factor is an additive constant that cancels out in the subsequent subtraction.

IADL indicates Instrumental Activities of Daily Living scale; MMSE, mini-mental state examination, NPI, Neuropsychiatric Inventory; SPPIC, Self-Perceived Pressure from Informal Care questionnaire; VAS, visual analogue scale.

important variables in both the multivariate and the forward analyses for explaining the 1-year square root total care costs.

\section{DISCUSSION}

Using the 12-month follow-up data of 219 patients with cognitive disorders, 4 variables were the most relevant predictors of annual care costs of patients suffering from dementia or a cognitive impairment: severity of cognitive function, experienced caregiver burden, patient sex, and functional ability.

These results are robust as 3 different analytic methods and a broad spectrum of disease severity variables and patient and informal caregiver social context variables were used. In addition, although the proxy good method does not include preference for providing informal care, it is a validated method to assess informal care costs. Therefore, this study adds value to the current COI studies and can thus be used to improve decision analytic modeling of AD and related dementias.

We identified patient sex, MMSE, IADL, and caregiver burden as the key variables to explain the variability of the care costs. This is in line with a recent review that identified caregiver burden as an important predictor for institutionalization. ${ }^{26}$ In this study sample, this is reflected by the positive correlation with home-based nursing care and care in a nursing home. Cost differences by patient sex

TABLE 5. Pooled Results of the Multivariate Regression Model Including Theoretical Variables Only to Explain 1-year Square Root Total

\begin{tabular}{|c|c|c|c|c|}
\hline & \multicolumn{4}{|c|}{ Multivariate Regression } \\
\hline & Beta & $\boldsymbol{P}$ & Back-transformed $\beta *$ & Confidence Interval Back-transformed $\beta *$ \\
\hline MMSE score $(0-30)$ & -2.53 & 0.001 & -918 & -1437 to -399 \\
\hline NPI score (0-144) & 0.69 & 0.016 & 252 & 52 to 452 \\
\hline IADL score $(0-14)$ & -4.31 & 0.057 & -1555 & -3049 to -61 \\
\hline SPPIC score (0-9) & 6.32 & 0.000 & 2349 & 1155 to 3543 \\
\hline Constant & 203.94 & 0.000 & - & - \\
\hline
\end{tabular}
Care Costs

* See the footnote of Table 4 for calculation details.

IADL indicates Instrumental Activities of Daily Living scale; MMSE, mini-mental state examination, NPI, Neuropsychiatric Inventory; SPPIC, Self-Perceived Pressure from Informal Care questionnaire. 
might be explained by differences in caregiving experience and approaches to caregiving that were likely to result in women experiencing more depressive symptoms and anxiety, more time spent caregiving, higher burden, and less support from other family members or friends. ${ }^{27}$ The strong relation between both MMSE and IADL and care costs from our analyses is in line with the literature. ${ }^{3,28,29}$

In contrast to the literature, behavioral problems and care $\operatorname{costs}^{30,31}$ were not significantly related in the multivariate and forward analyses. A plausible explanation is the significant correlation with the IADL (Pearson correlation $=-0.39$ ) that eliminates part of the variance explained by the NPI. Another explanation is that the NPI may not be sensitive to subtle changes. Additional analyses by replacing the total NPI with each individual item of the NPI only indicated that "irritability" was the only variable that predicted costs without any change in significance in the other variables. In addition, caregiver distress due to patient behavior, but not behavior in itself, is a risk factor for patient institutionalization. ${ }^{32}$ The number of comorbidities was not significant. Although the literature might suggest that this item is a cost predictor, it is not conclusive on this item. ${ }^{28,33}$ A possible explanation could be that part of the variance is explained by the experienced burden by the informal caregiver.

These differences from other studies may also be explained by sample differences with the complex patient group of this study that was in need of care on multiple domains.

This study is in line with the findings of previous research that informal care represents a considerable part of the care costs in dementia, ${ }^{28,34,35}$ which emphasizes the importance of applying a societal viewpoint to include all relevant care costs for patients with dementia. This could, for example, imply that if direct health care resources are diminished, these probably will be compensated by informal care.

\section{Limitations}

All outcome measures except the MMSE and activities of daily living were collected through personal interviews with the patient's proxy. It is unknown whether the proxy's response exactly represents the situation of the patient, because it is not known as to which measurement method (ie, patient, caregiver, or physician) is the most representative. $^{36}$

The study sample represents the 1-year care costs of patients after they received a diagnosis. This may limit long-term extrapolation of the cost data. Three possible causes for selection bias are the willingness of participants to participate in research, the general practitioner's inability to recognize all dementia patients in the general population, and the applied inclusion criteria of the MEDICIE study, which was not originally designed for a COI study analysis. These factors limit the generalizability, because institutionalized patients were excluded and costs were measured from the point of diagnosis under representing the cognitive impairment stage preceding dementia. Determinants of care costs may be different in the mild cognitive impairment stage, early dementia stage, and late dementia stage. Therefore, generalization of the results should be done with caution. This is a common problem of the bottom-up design in which not all typical disease events could have occurred in the sample population and the follow-up period of the study. Furthermore, clinical trial data of both the intervention and the control group were used. ${ }^{10} \mathrm{Al}-$ though it was controlled for additional costs and the total mean difference between both groups was $€ 23$, it might have limited the generalizability to the Dutch population. Finally, several factors, including unit costs, resource use, clinical practice, and patient case mix, were expected to generate some variation in the total cost estimates between countries. $^{37}$

\section{Implications for Modeling}

The findings of this study build on the evidence to recommend basing a decision model structure on cognitive function, functional ability, and behavior to model disease progression. ${ }^{8,9}$ Moreover, we identified sex and the burden of the informal caregiver as key variables for predicting square root annual total care costs for newly diagnosed patients adjusted for the 3 variables of disease severity. Taking into account the influence of sex on costs in a decision analytic model structure can provide a more precise prognosis of care costs and enables the estimation of demographical differences regarding a population. Including caregiver burden fully reflects the heterogeneity of disease progression. Most AD models describe the economic effects of a medical intervention, ${ }^{8}$ although they do not explicitly include caregiver burden. ${ }^{38-40}$ Nonetheless, several models included institutionalization and therefore might have comprised caregiver burden indirectly in the probability for institutionalization. ${ }^{41}$ For the evaluation of nonpharmacotherapeutic interventions, such as a diagnostic technique or caregiver support that could have an isolated effect on caregiver burden, it is important to include caregiver burden as this research indicates. The application of all recommended variables in a decision model could have implications for the choice of model type, for example, because of transparency issues. A recommendation for model type is, however, beyond the scope of this article.

\section{CONCLUSIONS}

Cognitive function, functional ability, caregiver burden, and patient sex are independently the most relevant explanatory variables of care costs of cognitive disorders. The findings stress the need for multicomponent decision models and correspond to current recommendations for decision analytic modeling to include cognitive function, functional ability, and behavior. In particular, this study adds the recommendation to include patient sex and caregiver burden to fully reflect the heterogeneity of disease progression. The results of this study may improve decision models and help policy makers to allocate scarce health care resources more efficiently.

\section{ACKNOWLEDGMENT}

This research was performed within the framework of CTMM, the Center for Translational Molecular Medicine (http://www.ctmm.nl), project LeARN (grant 02N-101).

Patient data used for the analyses were originally gathered in the MEDICIE study, ${ }^{10}$ a study funded by the Dutch Research Institute for Care-Medical Sciences (ZorgOnderzoek Nederland-Medische wetenschappen), grant 945-02-055.

The authors thank Alfons Kessels, Department of Clinical Epidemiology and Medical Technology Assessment at Maastricht University Medical Centre in The Netherlands, and Maiwenn Al, Medical Technology Assessment at Erasmus 
University Rotterdam, for their recommendations on statistical analysis.

\section{REFERENCES}

1. Wimo A, Prince M. World Alzheimer Report 2010 The Global Economic Impact of Dementia. 2010. Available at: http:// www.alz.co.uk/research/worldreport/. Accessed October 1, 2010.

2. Briggs AH, Claxton K, Sculpher MJ. Decision Modelling for Health Economic Evaluation. Oxford: Oxford University Press; 2006.

3. Tarricone R. Cost-of-illness analysis. What room in health economics? Health Policy. 2006;77:51-63.

4. Jonsson L, Wimo A. The cost of dementia in Europe: a review of the evidence, and methodological considerations. Pharmacoeconomics. 2009;27:391-403.

5. Quentin W, Riedel-Heller SG, Luppa M, et al. Cost-of-illness studies of dementia: a systematic review focusing on stage dependency of costs. Acta Psychiatr Scand. 2009;121:243-259.

6. Wimo A, Jonsson L, Gustavsson A, et al. The economic impact of dementia in Europe in 2008-cost estimates from the Eurocode project. Int J Geriatr Psychiatry. 2011;26:825-832.

7. Coduras A, Rabasa I, Frank A, et al. Prospective one-year cost-of-illness study in a cohort of patients with dementia of Alzheimer's disease type in Spain: The ECO Study. J Alzheimers Dis. 2009;19:601-615.

8. Cohen JT, Neumann PJ. Decision analytic models for Alzheimer's disease: state of the art and future directions. Alzheimers Dement. 2008;4:212-222.

9. Green C. Modelling disease progression in Alzheimer's disease: a review of modelling methods used for cost-effectiveness analysis. Pharmacoeconomics. 2007;25:735-750.

10. Wolfs CA, Dirksen CD, Kessels A, et al. Economic evaluation of an integrated diagnostic approach for psychogeriatric patients: results of a randomized controlled trial. Arch Gen Psychiatry. 2009;66:313-323.

11. Wolfs CA, Kessels A, Dirksen CD, et al. Integrated multidisciplinary diagnostic approach for dementia care: randomised controlled trial. Br J Psychiatry. 2008;192:300-305.

12. Folstein MF, Folstein SE, McHugh PR. "Mini-mental state". A practical method for grading the cognitive state of patients for the clinician. J Psychiatr Res. 1975;12:189-198.

13. Cummings JL, McPherson S. Neuropsychiatric assessment of Alzheimer's disease and related dementias. Aging (Milano). 2001;13:240-246.

14. Lawton MP, Brody EM. Assessment of older people: selfmaintaining and instrumental activities of daily living. Gerontologist. 1969;9:179-186.

15. EuroQol Group. EuroQol - a new facility for the measurement of health-related quality of life. Health Policy. 1990;16: 199-208.

16. Pot AM, van Dyck R, Deeg DJ. Perceived stress caused by informal caregiving. Construction of a scale. Tijdschr Gerontol Geriatr. 1995;26:214-219.

17. American Psychiatric Association. Diagnostic Criteria From $D S M-I V-T R$. Washington, DC: American Psychiatric Association; 2000.

18. Oostenbrink JBKM, Rutten FFH. Manual for costing: methods and standard costs for economic evaluations in health care. Amstelveen, The Netherlands: College voor zorgverzekeringen; 2004. [in Ducth].

19. van den Berg B, Al M, Brouwer W, et al. Economic valuation of informal care: the conjoint measurement method applied to informal caregiving. Soc Sci Med. 2005;61:1342-1355.

20. van den Berg B, Brouwer W, van Exel J, et al. Economic valuation of informal care: lessons from the application of the opportunity costs and proxy good methods. Soc Sci Med. 2006;62:835-845.
21. Briggs AH, Claxton K, Sculpher MJ. Decision Modelling for Health Economic Evaluation. Oxford: Oxford University Press; 2006.

22. Tabachnick BG, Fidell LS. Using Multivariate Statistics. 4th ed. Boston, MA: Allyn and Bacon; 2001.

23. Wimo A, von Strauss E, Nordberg G, et al. Time spent on informal and formal care giving for persons with dementia in Sweden. Health Policy. 2002;61:255-268.

24. Harrow BS, Mahoney DF, Mendelsohn AB, et al. Variation in cost of informal caregiving and formal-service use for people with Alzheimer's disease. Am J Alzheimers Dis Other Demen. 2004; 19:299-308.

25. Jones M. Models for Health Care. University of York. Available at: http://www.york.ac.uk/res/herc/documents/wp/ 10_01.pdf. Accessed November 15, 2011.

26. Gaugler JE, Yu F, Krichbaum K, et al. Predictors of nursing home admission for persons with dementia. Med Care. 2009; 47:191-198.

27. Connell CM, Janevic MR, Gallant MP. The costs of caring: impact of dementia on family caregivers. J Geriatr Psychiatry Neurol. 2001;14:179-187.

28. Jonsson L, Eriksdotter Jonhagen M, Kilander L, et al. Determinants of costs of care for patients with Alzheimer's disease. Int J Geriatr Psychiatry. 2006;21:449-459.

29. Wolstenholme J, Fenn P, Gray A, et al. Estimating the relationship between disease progression and cost of care in dementia. Br J Psychiatry. 2002;181:36-42.

30. Herrmann N, Lanctot KL, Sambrook R, et al. The contribution of neuropsychiatric symptoms to the cost of dementia care. Int J Geriatr Psychiatry. 2006;21:972-976.

31. Murman DL, Chen Q, Powell MC, et al. The incremental direct costs associated with behavioral symptoms in AD. Neurology. 2002;59:1721-1729.

32. de Vugt ME, Stevens F, Aalten P, et al. A prospective study of the effects of behavioral symptoms on the institutionalization of patients with dementia. Int Psychogeriatr. 2005;17:577-589.

33. Scuvee-Moreau J, Kurz X, Dresse A. The economic impact of dementia in Belgium: results of the National Dementia Economic Study (NADES). Acta Neurol Belg. 2002;102: 104-113.

34. Souetre E, Thwaites RM, Yeardley HL. Economic impact of Alzheimer's disease in the United Kingdom. Cost of care and disease severity for non-institutionalised patients with Alzheimer's disease. Br J Psychiatry. 1999;174:51-55.

35. Wimo A, Winblad B, Jonsson L. The worldwide societal costs of dementia: estimates for 2009. Alzheimers Dement. 2010;6: 98-103.

36. Tamim H, McCusker J, Dendukuri N. Proxy reporting of quality of life using the EQ-5D. Med Care. 2002;40:1186-1195.

37. Sculpher MJ, Pang FS, Manca A, et al. Generalisability in economic evaluation studies in healthcare: a review and case studies. Health Technol Assess. 2004;8:iii-iv. 1-192.

38. Caro JJ, Getsios D, Migliaccio-Walle K, et al. Assessment of health economics in Alzheimer's disease (AHEAD) based on need for full-time care. Neurology. 2001;57:964-971.

39. Francois C, Sintonen H, Sulkava R, et al. Cost effectiveness of memantine in moderately severe to severe Alzheimer's disease: a Markov model in Finland. Clin Drug Investig. 2004;24: 373-384.

40. Ward A, Caro JJ, Getsios D, et al. Assessment of health economics in Alzheimer's disease (AHEAD): treatment with galantamine in the UK. Int $J$ Geriatr Psychiatry. 2003;18: 740-747.

41. Torti FM Jr, Gwyther LP, Reed SD, et al. A multinational review of recent trends and reports in dementia caregiver burden. Alzheimer Dis Assoc Disord. 2004;18:99-109. 